\title{
Criteria 2000, A Case Study
}

\section{Michael Rudko}

Union College

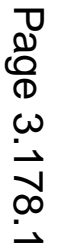




\begin{abstract}
Union College was one of the three institutions whose programs were evaluated in October 1997 using the ABET Criteria 2000 process. The paper, written from the point of view of the Electrical Engineering Department, describes the steps involved in the preparation for the visit, presents conclusions based on the visit, and identifies some issues which remain imponderable after it. The preparatory activities included the determination of the program objectives, of a curriculum designed to meet these objectives, and the identification of measurable outcomes and of an assessment strategy. The latter is used to measure the degree of success in meeting the program objectives as well as Criteria 2000 objectives [a]-[k]. The limited set of conclusions is based on the visit and on the exit interview which culminated it.
\end{abstract}

\title{
I. Introduction
}

Union College was one of the three institutions which underwent accreditation in 1997 using ABET Criteria 2000. The paper, written from the point of view of the Electrical Engineering Department, describes the steps involved in the preparation for the visit, presents conclusions based on the visit, and identifies some issues which remain imponderable after it. The preparatory activities included the determination of the program objectives, of a curriculum designed to meet these objectives, and the identification of measurable outcomes and of an assessment strategy. The latter is used to measure the degree of success in meeting the program objectives as well as Criteria 2000 objectives [a]-[k]. The preparatory activities at Union were more extensive than usual because they included a major revision of the curriculum. Late in the fall term 1993, Union College received a five-year, $\$ 750,000$ from the GE Foundation (now the GE Fund) to undertake a total redesign of the college's nearly 150-year old engineering programs. During the 1993-94 academic year, Dean Kenyon simultaneously led Union's curriculum project and chaired the Engineering Accreditation Commission of ABET where the origins of what would become the ABET Criteria 2000 were being established. The Union College engineering curricula were therefore developed in anticipation of the evolving Criteria 2000. The mission statement of the Division of Engineering was written to reflect the updated goals and objectives on which the new curriculum was based. Each of the departments then created its own mission statement together with its specific discipline-based goals and objectives.

\section{Mission and Objectives}

The mission and objectives of the Electrical Engineering program, together with the resulting curriculum, reflect both the perceived essence of the discipline and the relatively unique qualities 
which are particular to the institution. Union College is a small, predominantly undergraduate liberal arts college with engineering.

The mission of the program is, consequently, to provide the student with a solid basis in electrical engineering and the underlying mathematics and science within the framework of a liberal arts college. The graduate can be expected to be successful in seeking employment or pursuing graduate studies in the area of her/his specialty and, through the General Education requirements and the relatively large number of free electives, to be a cultured member of society and of the multicultural, multinational world to which we all belong. The program objectives were chosen to fulfill this mission. They are:

(1) To provide a grouding in mathematics, science and fundamental concepts in engineering. This core is designed to encompass areas, and develop analytical and applied skills which can be expected to form the basis of electrical engineering in the future.

(2) To give the students a more in-depth mastery of at least one area of electrical engineering.

(3) To instill in the students the ability to apply this knowledge in the analysis, design and testing of engineering systems, processes and components. This includes the ability to use the computer and appropriate software tools, a facility with laboratory techniques, and with the analysis and interpretation of data.

(4) To expose the students to engineering practice and to its ethical and societal aspects, and to make them proficient in communication skills. (5) To give the students a sense of how they and the profession tit into the context of history and its cultural manifestations. (6) To make the students aware of the multicural, multinational world of which they are members.

(7) To give the students the opportunity to explore areas of interest thus nurturing the quest to learn.

(8) To provide the opportunity for in-depth study of a second area of interest. Some examples are fulfilling the requirements for a minor, or even a major in another department, and preparing for medical school.

The above are consistent with the mission of the college which stresses the students' commitment to truth and to joy in learning, their knowledge of self and their historical awareness, and the pursuit of professional education in the context of a liberal arts college. As described in the introduction, these objectives also reflect the ABET Criteria 2000 document and, in particular, objectives [a]-[k]. Since the fulfillment of these ABET objectives as well as of those of the program is called for, it seems prudent to formulate objectives which incorporate both the institutional program objectives and, at least, the spirit of [a]-[k]. 


\section{Curriculum}

Given the number and diversity of program objectives, the electrical engineering curriculum must necessarily be viewed as a compromise: one whose components are chosen to produce the desired outcomes within a four- year program. Moreover, the areas encompassed by electrical engineering have burgeoned during the past several decades. This makes it impossible to incorporate in the core requirements either all subfields of the discipline, or all science and engineering science courses traditionally included in the program. Subject to these constraints the principal components of the curriculum are:

1) An introductory year-long freshman course, Fundamentals of Engineering. The purpose of the course is to introduce the student to the breadth of engineering and to some of its subdisciplines, to make the student proficient in the use of the computer, some software tools and programming, and to give the student a grounding in laboratory techniques and in the analysis and interpretation of data. The course also exposes first- year students to engineering practice and to its ethical and societal aspects, and develops proficiency in both written and oral communication skills. Of particular note is the fact that objectives 4, 5 and components of objective 3 are addressed as soon as the student enrolls in the program.

2) The required mathematics, science component of the program consists of the equivalent of four mathematics courses, two physics courses, and of a science elective. This requirement corresponds primarily to components of objective 1 . Three aspects should be emphasized. The exact content of the required courses is selected so that the subjects which are covered are reinforced in the subsequent program. The third science course is an elective. This offers the student the opportunity to choose a course in a field of interest and opens the possibility of including biology, an area of increasing importance, in the core requirements. Finally, students with an adequate high school preparation in mathematics enroll in a sequence of three integrated mathematics, physics courses. They are therefore simultaneously exposed to mathematics and to its applications.

3) The core requirements include a course in mechanics which covers elements of statics and dynamics. This course builds of the freshman year physics course and presents fundamental engineering concepts which are reinforced in upper level, primarily control systems, courses. It helps to fulfill objective 1 .

4) The electrical engineering core requirements consist of ten courses whose coverage includes electrical circuits, an introduction to computers and logic design, semiconductor devices and electronics, analog and discrete systems, control systems, analog and digital communications, an introduction to electromagnetic engineering and probability. Computer usage is an important element of all the courses and the design component is emphasized. Also 
mathematics are introduced in the context of applications. Thus, the Laplace transform and system concepts are introduced in conjunction with circuit analysis in a

Circuits and Systems course. Fourier series and the Fourier transform are covered in the course on analog communications. Elements of probability and random process theory are taught together with the main topics of digital communications. As in the freshman year integrated math/physics courses these courses are structured in an integrated math/application form in the belief that engineering students best learn mathematics in the context of their applications. The subject areas included in the core requirements are chosen to provide the student with sufficient breadth in the fundamental areas of modern electrical engineering and the associated analytical techniques. The courses and laboratories, together with the required written and oral reports, and design projects are chosen to fulfill aspects of objectives 1, 3 and 4 .

5) The senior level capstone design course encompasses several components and reinforces skills and techniques developed throughout the curriculum. It includes a seminar which exposes students to issues of professional ethics and safety through case studies, invited speakers and writing assignments. It requires the open-ended design of a device, subsystem or system, a written report and an oral presentation. The report must include an analysis of the societal impact of the device or system based on the device and must present a historical perspective on its development. As such, the course contributes significantly to the fulfillment of objectives 2, 3, 4 and 5 .

6) The depth requirement of the curriculum, which consists of three courses, directly addresses objective 2 .

7) The General Education portion of the curriculum includes Freshman Preceptorial, a two-course history sequence, two associated literature/civilization courses and a social science elective. All students must participate in an international experience and satisfy the Union College writing across the curriculum requirements. Freshman Preceptorial introduces fundamental works of western and non-western civilization, emphasizes the importance of point of view and of critical analysis, and develops oral discussion skills and writing. The history sequence allows the student to place himself/herself in a historical perspective and relate history to its cultural manifestations through the associated literature/civilization courses. The social science elective exposes the student to one area of social science such as anthropology, sociology, political science or economics. Finally, the foreign component is designed to make the student aware of, and comfortable in, a multicultural, multinational world. It can be fulfilled through a term abroad, a foreign exchange program, an international internship, a virtual term abroad or three courses which emphasize these aspects. Consequently, the General Education portion of the curriculum plays an important part in meeting the goals in Objectives 4, 5 and 6 . 8) The curriculum includes a relatively large number of free electives. This number can be as large as eight and depends on the mode chosen to fulfill the international component of the General Education requirements and on the level of high school mathematics preparation. The department feels that this flexibility is very important. It permits the student to explore, in depth, 
areas within and outside engineering thus encouraging the student to develop a desire to learn. Many options become possible. An electrical engineering student can minor or even, in some cases, major in computer science, mathematics, English, economics or another area of interest. The student who wishes to pursue a medical career can use the free electives to meet the requirements of a pre-med program. This component serves to meet objectives 7 and 8 .

\section{Assessment}

Union College has had a number of assessment procedures in place form any years. Among those are required course end evaluations, which are used in the the tenure/promotion review process, and solicitation of feedback from students, employers, and alumni. Curriculum assessment was undertaken as part of the periodic curriculum reviews, and as part of the selfstudy process for each ABET visit. Other than the end of course evaluations, evidence gathered was largely anecdotal. With the adoption of Criteria 2000, the process needs to be both more formal and more rigorous. It should include input from all program constituencies and assess the achievement of the program objectives described above and of objectives [a]-[k] of the Criteria 2000 ABET document. An exhaustive assessment which would include all combinations of constituencies, objectives, outcomes and levels would be prohibitively time and labor intensive. The overwhelming nature of the problem can be glanced from the following. Constituencies which can provide input to the process include students, faculty, employers, recruiters, graduate and professional schools, licensing boards, the Dean's Engineering Council and the Engineering Accreditation Commission. Assessments can be grouped into, at least, the following categories: -course objectives -program objectives -objectives (a)-(k) -support infrastructure which includes

1. Laboratory equipment and facilities

2. Computer facilities

3. Technical support

4. Library

5. Career Development Center

6. Term Abroad Office

7. Internship/Exchange coordination

8. Advising

-faculty quality -effectiveness of prerequisite structure.

Outcomes can be measured on a course, program year, and whole program level. The latter can be carried out by graduating seniors and by alumni at some time intervals after, graduation. It is 
therefore imperative that a subset of all possible assessments be selected which is relatively small but can meet the objectives of the whole process, namely, to modify the program requirements, improve the support infrastructure, and also revise the particular outcomes used and their measurement, and the entire assessment process as required. The assessments which have been selected for implementation at Union include:

-end of course student evaluation of faculty effectiveness, course objectives, relevant program and ABET [a]-[k] objectives, the effectiveness of prerequisites and the quality of applicable support infrastructure elements.

-end of course faculty assessment of the success in meeting course and program objectives and the effectiveness of prerequisites.

-end of year student survey to assess the success in meeting the objectives on a yearly and whole program basis.

-exit interviews of graduating seniors.

-alumni surveys at rolling five-year intervals.

-student and employer surveys to evaluate coop and internship experiences, and informal employer and recruiter assessment of curriculum quality.

-student and International Studies Office assessment of the required international

experience. To date, several of the assessment instruments have been put in place. An assessment of the first year of the curriculum has been carried out. It was based on portfolios of student work, end of term surveys, and an end of year survey. A number of changes in the freshman year Fundamentals of Engineering course were instituted as a result. Graduating seniors were interviewed and were asked to fill out surveys. Alumni from three classes at fiveyear intervals from graduation were surveyed. The assessments from the two latter groups were based on the old curriculum. The results were gratifying since they reinforced many of the changes that were made in the new curriculum, such as, the added emphasis on writing, on oral communication, and on the senior project experience. It should be pointed out, however, that the rate of response of the alumni group was relatively low, of the order of twenty percent. The courses of the new curriculum which were offered during the fall 1997 term were extensively evaluated. The results of these evaluations are being presently analyzed.

\section{Conclusions}

The ABET on-site visit occurred in October 1997. A true conclusion to this paper would be a presentation of the results of the visit. At this time, these are not officially known, but one is hopeful. A partial conclusion can be made based on the preparations for the visit described above and on a sense glanced during it and throughout the process. The new ABET Criteria 2000 offer each institution and program an opportunity to define objectives and a resulting curriculum which fit its identity. This is significant since it provides the program the possibility to define itself within an institutional and professional framework. There is, of course, a price, or 
responsibility, associated with this opportunity and limitations placed on implementation. The program must define objectives and establish a process wherein the satisfaction of these objectives, as well as those of ABET, is measured and the results of the measurements are used to modify the curriculum, the objectives and the the assessment. The greatest difficulty is the definition of a sufficient, but not overwhelming, number of outcomes whose measurement provides real information. There is a danger in making the process driven by present and former student surveys since the input from both groups tends to reflect particular experiences and, not necessarily, more general truths. Although the ABET 2000 Criteria are more flexible than their predecessor, the fact that programs must still satisfy credit hour or percentage minima in engineering, math/science and liberal arts contents as well as more specific program criteria needs to be kept in mind. From the viewpoint of Union College, we are thankful for the added flexibility and believe that we have put it to good use within our institutional framework, but the new process did require a considerably larger effort than the one it replaced. Hopefully, as we all become more versed in assessment techniques and in the implementation of the ABET 2000 criteria this will cease to be the case.

MICHAEL RUDKO

Union College

Electrical Engineering Department

Schenectady, NY 12308 